\title{
Gender, class, employment status and social mobility following spinal cord injury in Denmark, the Netherlands, Norway and Switzerland
}

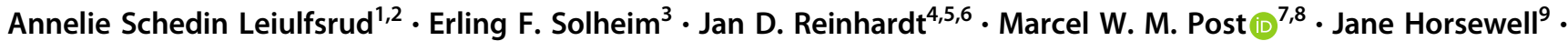 \\ Fin Biering-Sørensen ${ }^{10} \cdot$ Håkon Leiulfsrud $^{3}$
}

Received: 1 May 2019 / Revised: 26 August 2019 / Accepted: 29 August 2019 / Published online: 1 October 2019

(c) The Author(s), under exclusive licence to International Spinal Cord Society 2019

\begin{abstract}
Study design Cross sectional survey of 1055 persons with spinal cord injury (SCI) in Denmark, the Netherlands, Norway and Switzerland.

Objectives (1) To analyse the employment levels of people of working age with SCI, including possible gender differences. (2) To study the relevance of occupational class before SCI and its impact on employment and occupational class after SCI. Setting Members of national SCI consumer associations.

Methods Employment status and social mobility after SCI was regressed on occupational class before SCI, using multinomial and binary logistic regression analysis of employment, while controlling for other explanatory variables to employment after SCI and demographic characteristics.

Results Employment levels after injury were similar for men and women in each of the four nations, but Dutch women had significantly lower scores on predicted employment than Dutch men. Employment and social mobility trajectories were heavily in favour of middle-class occupations. Gender differences in employment status at the time of study primarily occurred among those in working-class occupations before SCI, with men less likely than women of being non-employed. Working-class men were significantly more likely than working-class women to retain a working-class occupation at the time of study, and although non-significant, to attain a middle-class occupation after SCI.

Conclusion There was little variation in employment by gender within and across countries but significant differences between working-class and middle-class occupations before and after injury. The results suggest that targeted employment measures should be particularly invested in the rehabilitation of women in working-class occupations.
\end{abstract}

Deceased: Jane Horsewell

Supplementary information The online version of this article (https:// doi.org/10.1038/s41393-019-0356-3) contains supplementary material, which is available to authorized users.

Annelie Schedin Leiulfsrud

annelie.s.leiulfsrud@ntnu.no

1 Department of Neuro Medicine and Movement Science, Faculty of Medicine and Health Sciences, NTNU-Norwegian University of Science and Technology, Trondheim, Norway

2 Spinal Cord Unit, Department Physical Medicine and Rehabilitation, St Olav's University Hospital, Trondheim, Norway

3 Department of Sociology and Political Science, NTNU, Trondheim, Norway

4 Institute for Disaster Management and Reconstruction, Sichuan University, Chengdu, China

5 Swiss Paraplegic Research, Nottwil, Switzerland
6 Department of Health Sciences and Health Policy, University of Lucerne, Lucerne, Switzerland

7 Center of Excellence for Rehabilitation Medicine, UMC Utrecht Brain Center, University Medical Center Utrecht and De Hoogstraat Rehabilitation, Utrecht, the Netherlands

8 University of Groningen, University Medical Center Groningen, Department of Rehabilitation Medicine, Groningen, the Netherlands

9 Swiss Paraplegic Association, Nottwil, Switzerland

10 Neuro Science Center, Copenhagen University Hospital, Copenhagen, Denmark 


\section{Introduction}

Despite ambitious programmes and the investment of abundant resources in employment support measures, most European countries still have a considerable employment gap between people with and without a disability [1-3]. This employment gap represents a problem for both society and those with a disability who seek employment [2]. The conventional approach in the fields of medical rehabilitation and public health is to focus on the person's inability to perform physically demanding tasks and on various types of barriers, including inaccessibility of the work place, match of job content with functional ability or lack of sufficient support systems [3-9]. Economic incentives and disincentives to work, including economic compensation systems and mechanisms, are frequently cited in the medical and public health literature on employment and disability $[1-3,10]$.

Surprisingly, little research has been devoted to understanding how social mechanisms are intertwined with different labour market and welfare regimes [11-14]. In the welfare, social policy and health inequality literature Denmark and Norway are assigned to a Nordic or social democratic welfare regime [11-13], which differs from the liberal and conservative welfare regimes, including a universal social security system, less poverty and more equal income distributions, state driven activation measures and the structuring of postindustrial employment careers. In recent years Switzerland has gone from a more liberal model relying on private insurances and market mechanisms towards a more conservative welfare regime model with the family as the main welfare provider $[1,13]$. In most comparative analysis of welfare regimes, the Netherlands emerges as a hybrid between the Nordic/social democratic model and the conservative model $[11,13]$.

Employment gaps between those with and without a disability are of interest in this context as a possible sign of discrimination and social exclusion, and in how each welfare system succeeds at employing those with a reduced work ability [2, 3]. National differences in how social welfare and medical systems are organised may either increase the pressure on those with reduced work ability to be economically active or ease the financial burden of nonemployment $[1,3,10,11,14]$. Furthermore, those hampered by a disability may have to start a new occupational career, which could require vocational rehabilitation or studies to earn a secondary or tertiary degree. Success or failure to acquire such qualifications could lead to upward or downward social mobility.

In addition, countries may diverge in their prevention or facilitation of women's participation in the labour market
[15]. Employment rates for women and men respectively in the general population reported by Eurostat were $72.2 \%$ and $79.5 \%$ in Denmark, $77.8 \%$ and $78.6 \%$ in the Netherlands, $77.3 \% 82.4 \%$ in Norway, and 75.3 and $86.3 \%$ in Switzerland [16]. These figures refer to those aged 20-64 in 2012. Part-time employment was almost twice as high in the Netherlands (46.6\%) and Switzerland (37.5\%) compared with Denmark (20.9\%) and Norway (23.4\%) [16]. These country and gender differences in employment and parttime work are important because they relate with more conventional gender roles and the breadwinner model, substantial gender gaps in pay, career trajectories and pensions $[15,17]$.

Previous research on gender differences in employment after a spinal cord injury (SCI) in Europe and North America is divergent, either finding somewhat higher employment levels for men or no differences [4-9]. Substantially fewer but more consistent results have been published on the impact of social class, showing that white-collar employees more often than blue-collar employees return to work [7-9], and younger individuals switch to higher education to enhance their employment chances [7-9].

Gender and occupational class represent social mechanisms that go beyond individual characteristics and barriers to understand employment and job trajectories after SCI [8]. A focus on the gender-occupational class nexus is rare within SCI research. In addition, occupational class and gender are also predictors of life chances and how society, the labour market, the welfare system and the medical system, facilitate or discriminate against different social groups [12, 14, 15, 17-19].

This paper has two aims. First, we study the employment levels of people with SCI in Denmark, the Netherlands, Norway and Switzerland, including possible gender differences. Second, we study the impact of occupational class before SCI on employment and occupational class after SCI. Based on the literature on disability and employment in the general population [1-3] we specify five hypotheses: Men are more likely than women to be employed after SCI (H1a), and also to remain in employment after SCI (i.e., until the time of study) (H1b) [1-3, 7-9]. Those who were employed in middle-class occupations before SCI are more likely to be employed at the time of study (H2) [7-9]. Irrespective of pre-injury occupational class those in employment post injury are more likely to work in middleclass occupations (H3) [8, 9]. Those in middle- class occupations pre-injury are more likely than those in working-class occupations pre-injury to be employed (H4) and to obtain or retain a middle-class occupation after SCI at the time of study (H5) [4-9]. Furthermore, variations by gender and occupational class in employment and social mobility will be reported and discussed. 


\section{Methods}

The study "International Labour Market Integration Assessment in SCI" (ILIAS-SCI) collected survey data in 2012 in Denmark, the Netherlands, Norway and Switzerland. After approval by national or regional ethical committees the project was carried out in collaboration with national SCI consumer associations. The data were collected with a pen and paper or a web-based self-report questionnaire in three countries and web based only in Denmark. The response rates varied from 45 to 55\% (average 50\%). Only working age (20-64 years) association members were included in the current analysis, with 126 respondents from Denmark, 360 from the Netherlands, 264 from Norway, and 305 from Switzerland $(N=1055)$.

\section{Classification of occupational class}

Employment status and job titles were used to operationalise the European Socioeconomic Classification (ESeC) for occupational class before SCI and at the time of study [20]. Due to small sample sizes for some occupational classes, we only distinguish between middle- and workingclass occupations, and those 'not employed'. Middle-class occupations consist of upper and lower professionals and managers, upper routine non-manual workers, the self-employed and employers. Working-class occupations consist of skilled, semi-skilled and unskilled workers, foremen, and lower routine non-manual workers.

\section{Outcome variables}

First, we define two outcome variables measuring employment status after SCI (ever employed versus never employed after SCI) and employment status at the time of the study (employed versus not employed), respectively. Our definition of employment is similar to that of the International Labour Organisation, i.e., paid work for a minimum of $1 \mathrm{~h}$ per week, including self-employment and unpaid family workers.

Second, as our third outcome variable we combine information about past employment after SCI with occupational class at the time of study. Accordingly, we created four categories: currently employed in (1) working-class occupations or (2) middle-class occupations, (3) employed after SCI but not employed at the time of study, and (4) never employed after SCI.

\section{Independent variables}

Our main predictor variables were occupational class before SCI, coded as 'not employed', 'middle-class occupation', and 'working-class occupation', country and gender. Control variables were age and age at SCI, tetraplegia versus paraplegia, incomplete versus complete injury, vocational rehabilitation (yes/no), being able to continue to work in the same organisation after SCI ('yes, able to continue in same organisation', 'not working or no information about employment before SCI' and 'not able to continue working in the organisation'), and level of education ('primary', 'secondary' and 'tertiary' education). The choice of control variables is consistent with factors included in previous SCI studies aimed at studying labour market participation, including a previous publication using the Norwegian data [4-9].

\section{Analysis}

Multinomial and binary logistic regression analyses with robust standard errors were used to analyse the effects of occupational class and gender on our three outcome variables while adjusting for the above specified control variables. An age-square polynomial to adjust for increasing and shrinking employment by age was also included. The results are presented as plots showing predicted probabilities of employment and/or class at the time of study by country or class before SCI for men and women, respectively. We interpret the results as 'inference by the eye' [21] by studying whether or not the $95 \%$ confidence intervals overlap.

Descriptive statistics by country and gender are presented in Table 1. Complete regression results and all predicted probabilities visualised in Figs. 1-3 can be found in Tables A.1-A.4 in the online appendix.

\section{Results}

Unadjusted employment rates showed small differences across the countries, with 70-73\% of respondents employed at some point in time after SCI. However, at the time of study, the employment rates were lower, with $55 \%$ for Switzerland, 56.5\% for Denmark, 51\% for the Netherlands, and only $48 \%$ in Norway. Further descriptive statistics are shown in Table 1.

Figure 1 presents predicted probabilities of (a) having been employed after SCI and (b) being employed at the time of study by country and gender after adjusting for factors associated with employment after SCI. In three of the countries there were no significant gender differences in the probabilities of being employed at some stage after SCI. Only Dutch women at the time of study stood out from the more general pattern with a statistically significant lower employment rate than Danish women, and men in all four countries. In sum, we only found one gender and crosscountry difference in one of the two regressions. Thus, we do not find support for hypothesis $\mathrm{H} 1 \mathrm{a}$, that men are more likely than women to be employed after SCI, and in three of 
Table 1 Descriptive statistics of core variables by country. Mean (standard deviation), minimum and maximum, or column percentages

\begin{tabular}{|c|c|c|c|c|c|c|c|c|c|c|c|c|}
\hline & \multicolumn{3}{|c|}{ Denmark $(N=126)$} & \multicolumn{3}{|c|}{ Netherlands $(N=360)$} & \multicolumn{3}{|c|}{ Norway $(N=264)$} & \multicolumn{3}{|c|}{ Switzerland $(N=305)$} \\
\hline & Mean (sd) & Min & Max & Mean (sd) & Min & Max & Mean (sd) & Min & Max & Mean (sd) & Min & $\operatorname{Max}$ \\
\hline Age & $50.5(10.3)$ & 18 & 64 & $49.4(10.2)$ & 22 & 64 & $47.8(10.9)$ & 21 & 64 & $47.7(10.7)$ & 18 & 64 \\
\hline Age at onset of SCI & $32.8(14.1)$ & 3 & 61 & $32.2(13.2)$ & 1 & 62 & $27.8(12.5)$ & 0 & 60 & $29.4(12.2)$ & 1 & 60 \\
\hline Men & 63.5 & & & 67.5 & & & 67.4 & & & 71.1 & & \\
\hline Women & 36.5 & & & 32.5 & & & 32.6 & & & 28.9 & & \\
\hline \multicolumn{13}{|l|}{ Education } \\
\hline Primary & 43.7 & & & 22.8 & & & 43.9 & & & 29.2 & & \\
\hline Secondary & 22.2 & & & 24.4 & & & 32.6 & & & 43.9 & & \\
\hline Tertiary & 34.1 & & & 52.8 & & & 23.5 & & & 26.9 & & \\
\hline Paraplegia & 40.5 & & & 35.0 & & & 36.4 & & & 30.5 & & \\
\hline Tetraplegia & 59.5 & & & 65.0 & & & 63.6 & & & 69.5 & & \\
\hline Complete injury & 34.9 & & & 43.6 & & & 51.9 & & & 53.4 & & \\
\hline Incomplete injury & 65.1 & & & 56.4 & & & 48.1 & & & 46.6 & & \\
\hline \multicolumn{13}{|l|}{$\mathrm{ESeC}$ before SCI } \\
\hline Not employed & 20.6 & & & 31.4 & & & 36.7 & & & 24.9 & & \\
\hline Working class & 33.3 & & & 18.3 & & & 34.1 & & & 31.8 & & \\
\hline Middle class & 46.0 & & & 50.3 & & & 29.2 & & & 43.3 & & \\
\hline Employed after SCI & 69.8 & & & 72.2 & & & 73.1 & & & 69.8 & & \\
\hline Employed at the time of study & 56.4 & & & 50.8 & & & 48.1 & & & 54.8 & & \\
\hline \multicolumn{13}{|l|}{ Employment status at the time of study } \\
\hline Never employed after SCI & 30.2 & & & 27.8 & & & 26.9 & & & 30.2 & & \\
\hline Previously employed after SCI & 13.5 & & & 21.9 & & & 25.0 & & & 15.1 & & \\
\hline Working class at the time of study & 8.7 & & & 7.8 & & & 9.1 & & & 14.1 & & \\
\hline Middle class at the time of study & 47.6 & & & 42.5 & & & 39.0 & & & 40.7 & & \\
\hline
\end{tabular}

'Vocational rehabilitation' and 'able to continue working in same organisation' were also included in the regression analysis models

ESeC The European Socioeconomic Classification, SCI Spinal cord injury

four countries we did not find support for hypothesis $\mathrm{H} 1 \mathrm{~b}$, that men were more likely than women to be employed at the time of study.

Next, we extend the analysis by differentiating those working at the time of study in either working-class or middle-class occupations. The regression results (Table A.2) are presented in Figs. 2-3 (see also Table A.4).

The least likely outcome was to be employed in a working-class occupation, followed by having been employed after SCI but not anymore at the time of study. In all four countries working in a middle-class occupation was significantly more likely than working in a working-class occupation or previously employed after SCI. The only exception was among Dutch women, where the middleclass outcome was not significantly different from previously employed (Fig. 2). These results support hypothesis $\mathrm{H} 3$; if returning to work after SCI, both men and women most likely work in a middle-class occupation.

Figure 3 shows the predicted employment and class outcomes at the time of study (see also Table A.4). If we focus on the 'never employed' after SCI outcome seen to the far left within each respective plot in Fig. 3, we see no significant gender or class differences between those who were in working-class positions, middle-class positions or 'not employed' before SCI. The confidence intervals for all six predictions overlap. Thus, we did not find support for neither hypothesis $\mathrm{H} 2$ nor hypothesis $\mathrm{H} 4$; in our data men or women who worked in middle-class occupations before SCI were not more likely to be employed after SCI in general or compared with those who worked in workingclass occupations before SCI.

Next, we focus our attention to the variation seen within each of Fig. 3's six plots. Among those who had a middleclass occupation before SCI, we see nearly identical results for men and women. More than half were still working in middle-class occupations at the time of study, approximately a third were never employed again, approximately a fifth returned to work but were no longer employed at the time of study, and a tiny proportion had experienced downward social mobility. Among those who worked in a workingclass occupation before SCI, all four outcomes were predicted equally among men, at approximately one quarter each. Thus, a quarter experienced upward social mobility. Among women with a working-class occupation before SCI 
Predicted probability employed after $\mathrm{SCI}$ Men by country

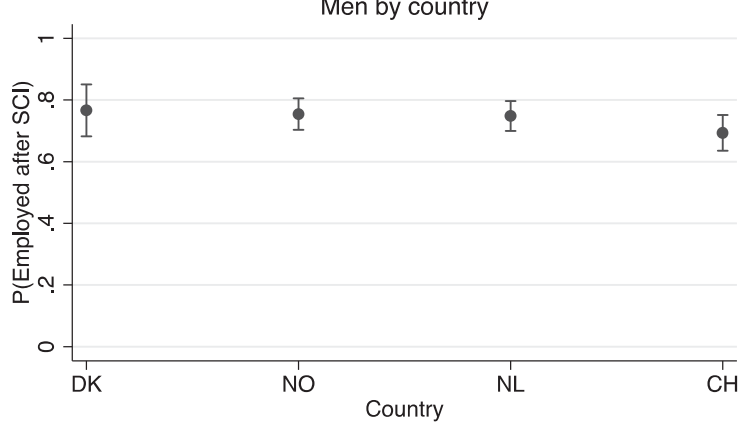

Predicted probability still employed after SCI Men by country

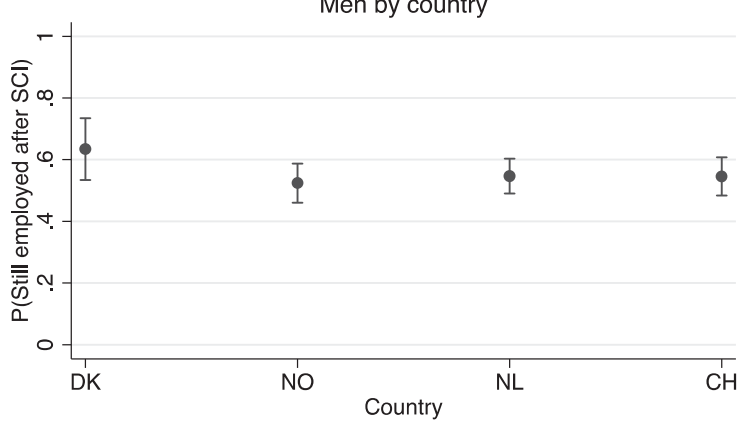

Predicted probability employed after $\mathrm{SCl}$ Women by country

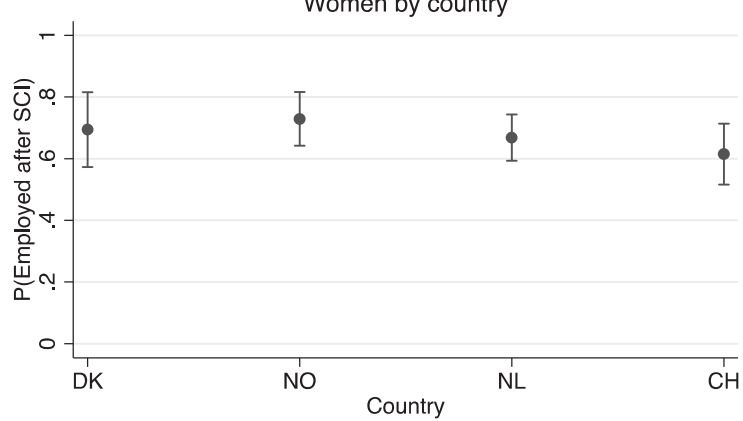

Predicted probability still employed after SCI Women by country

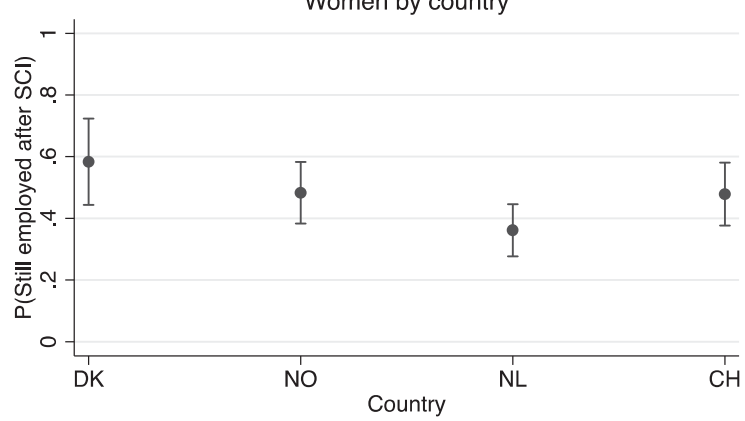

Fig. 1 Predicted probabilities of ever having been employed after SCI (upper) and still being employed at time of study (lower). Men and women by country

\section{Predicted probability employment status}
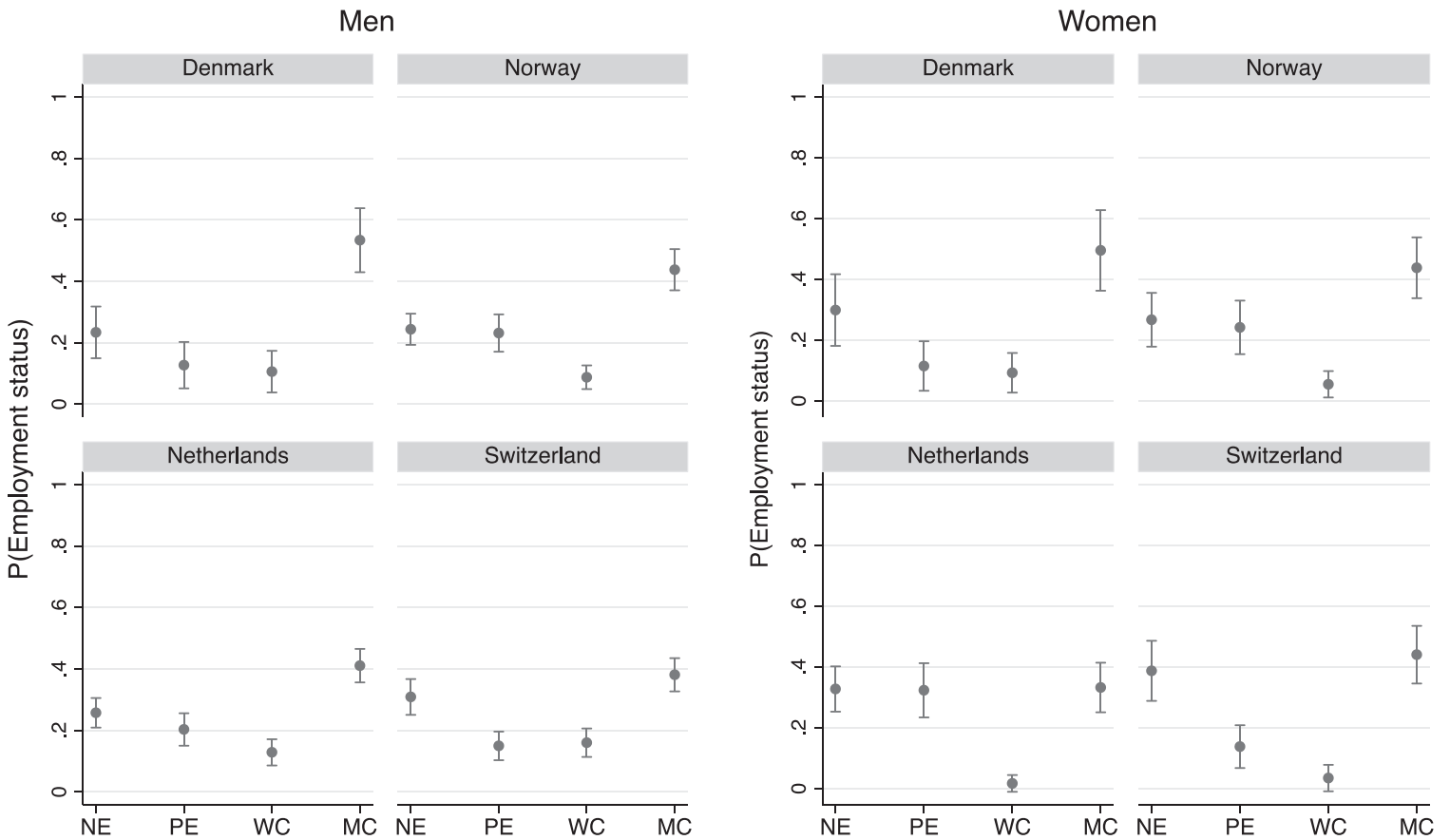

Note: $\mathrm{NE}=$ Never employed $\mathrm{PE}=$ Previously employed $\mathrm{WC}=$ Working class $; \mathrm{MC}=$ Middle class

Fig. 2 Predicted employment status at the time of the study by country and gender, controlling for age, age at SCI, education, paraplegia versus tetraplegia, complete versus incomplete injury, receiving vocational rehabilitation or not, and able to continue working in the same organisation 
Predicted probability employment status
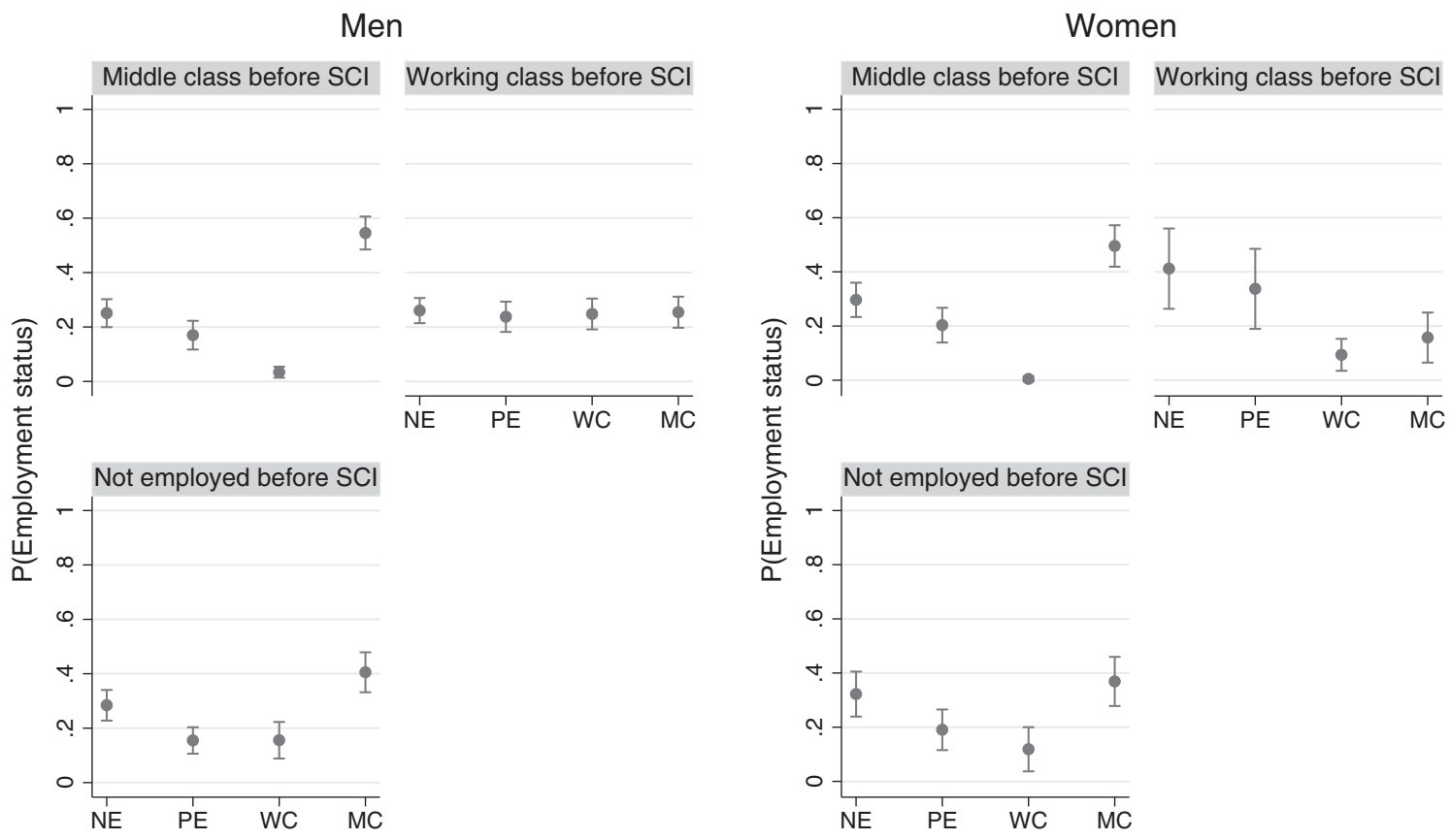

Note: $\mathrm{NE}=$ Never employed; PE $=$ Previously employed; $\mathrm{WC}=$ Working class; $\mathrm{MC}=$ Middle class

Fig. 3 Predicted employment status by occupational class before SCI by gender, controlling for age, age at SCI, education, paraplegia versus tetraplegia, complete versus incomplete injury, receiving vocational rehabilitation or not, and able to continue working in the same organisation

there was substantial variation. Four out of ten never returned to work, three out of ten had been in employment but were not employed at the time of study. Only fifteen out of a hundred had a middle-class occupation, and one out of ten worked in a working-class occupation.

These results support hypothesis $\mathrm{H} 5$ for both men and women; working in a middle-class occupation rather than a working-class occupation prior to SCI increases the chance of gaining or retaining a middle-class occupation after SCI.

Moreover, the gender difference that we see in Fig. 3 reveals a distinctive and important gender difference in employment and social mobility between men and women positioned in working-class occupations before SCI, which also implies a larger intra-sex class difference among women than among men, i.e., a more distinctive difference between women in working versus middle-class positions before SCI with respect to their employment and mobility patterns after SCI.

\section{Discussion}

The differences in employment patterns for people with SCI are surprisingly small between the four countries. All four countries score highly on welfare expenditure and activation measures [1-3]. The differences between the countries are most likely related to family and gender ideology, where women in Norway and Denmark are more expected than women in the Netherlands and Switzerland to be in employment on par with men $[8,15,16]$.

\section{Gender and employment after SCI}

The gender differences were small and only Dutch women had a statistically significant lower predicted employment rate, at the time of study. This result does not support our first hypothesis $\mathrm{H} 1$, predicting that men are more likely to be employed after SCI. The result raises the question about what causes this absence of a gender gap in employment; a gap found in the general working-age population in most European nations [15-17]. Follow up studies should clarify the proportion working part time and precarious work, such as fixed contracts, and the methods applied among people with SCI to find jobs compared with the general workingage population.

\section{Occupational class and social mobility after SCI}

Contrary to our expectations we did not find support for $\mathrm{H} 2$ and $\mathrm{H} 4$, i.e., that those with a middle-class occupation before SCI are more likely to be employed at the time of study, both in general and relative to those in working-class 
occupations before SCI (Fig. 3). We found support for hypothesis $\mathrm{H} 3$, i.e., those in employment after SCI are more likely to work in middle-class occupations (Fig. 2).

Finally, we found support for hypothesis H5; both men and women in middle-class occupations before SCI had significantly higher chances of being employed in middleclass occupations at the time of study. Men and women not employed before SCI were also significantly more likely to be employed in middle-class occupations than those who worked in working-class occupations before $\mathrm{SCI}$ at the time of study (Fig. 3). This result probably reflects that some who were not employed before SCI were students or homeworking despite holding or later acquiring a tertiary degree.

\section{Gender and social mobility after SCI}

In addition to the hypotheses we tested, we noticed some important gender differences in relation to employment and social mobility. Successful upward social mobility among men in working-class jobs before SCI is an important reason why men regardless of occupational class before SCI have similar level of employment at the time of study. Women in working-class jobs before SCI stood out from both women in middle-class positions and men in workingclass positions before SCI, with a majority either never having been employed or no longer working at the time of study, few holding on to a working-class position after SCI, and were substantially (but not statistically significant) less likely than working-class men to have experienced upward social mobility (Fig. 3).

Based on our knowledge of labour markets for people with SCI in each country, it could be that working-class men have more favourable human capital, such as highdemand skills, and thus receive more support from their employers [8]. Furthermore, vocational rehabilitation programmes might better match the needs of male-dominated occupations [8]. This link between gender and class may also, in line with previous research, represent a case of a "double burden" regarding the family-work nexus $[15,17,22,23]$. Whereas working-class men are less burdened with family obligations, working-class women have less flexibility, autonomy and control over their job, making it more difficult for them to combine family and work commitments. Hence, women might more easily withdraw and take on family roles if the option is to struggle with the double burden due to the combination of reduced work ability and family commitments [15]. Decisions whether to stay or remain in employment is also highly contingent on income, education and public norms that favour men's careers at women's costs [15, 17].

Our analysis identifies class, mobility and gender differences in working-class women's disfavour that needs attention in future research [17, 24]. Given the gender segregation (with respect to sector, occupation and type of job) in the labour market in all four countries [15, 17], it is of interest to study the jobs and career options most men and women with SCI acquire after SCI.

Going beyond individualistic explanations, future research should explore the partner's role and the household's combined resources and work-family-coping strategies in relation to return to employment when living with reduced work ability or return to employment after SCI. A lack of skills and human capital in high demand may explain why having a working-class position at the time of the injury could be a trap, especially among women. Higher education and the relatively generic skills typically required in middle-class jobs are clearly favourable to work- and employ-ability. Our study suggests this is particularly important to follow up for Dutch women and women with a working-class job prior to SCI. Moreover, our results seem to question whether the existing vocational rehabilitation programmes are sufficiently successful at improving employment and mobility chances among women with a working-class job before injury.

\section{Methodological strengths and limitations}

The harmonisation of variables across the four national surveys enabled a direct comparison of results across countries. For a study on people with SCI the sample size is large, but methodologically the sample size is nevertheless fairly small and not without problems. The small sample sizes increase the risk of Type II errors despite substantially significant sample results. Class categories were merged due to small cell sizes. This simplified the interpretations and increased harmonisation across countries, but prevented us from studying the role of class and social mobility more detailed. Due to data limitations part-time workers could not be identified, which could explain the small and nonsignificant gender differences in employment. If full-time is the norm for men while part-time is more acceptable among women, it could be easier for women than men with SCI to be employed. Future research should attempt to collect larger samples and differentiate between part- and full-time workers. Our data and conclusions are limited to four European countries with modern economies and developed welfare states, with substantial social benefits to individuals with disabilities. How less developed welfare states and health systems fare in comparison to our four countries should also be explored in future research.

\section{Policy recommendations}

The results suggest that more and better-targeted employment measures should be invested in rehabilitation for those 
with working-class occupations, especially among workingclass women and women in the Netherlands with SCI. The sharp drop in employment after SCI until the time of study in Norway suggests that there is a high potential for prolonging the careers of this group if sufficient incentives and support are in place.

\section{Data availability}

Data are stored at the Swiss Paraplegic Research Centre in Nottwil and were later adjusted for comparative purposes by the authors.

Acknowledgements We are grateful to all the participants of the ILIAS-SCI survey for their time and effort spent in responding to the questions.

Funding The data analysis was sponsored by a grant from the Spinal Cord Unit at St. Olav University Hospital. The project has previously received financial support from Swiss Paraplegic Research. The Dutch part of ILIAS was supported by the "Revalidatiefonds" (now: Handicap.nl), grant number 2012006.

Author contributions All authors have actively contributed to the intellectual content of the article. The corresponding author had full access to the data and had final responsibility for the decision to submit for publication.

\section{Compliance with ethical standards}

Conflict of interest The authors declare that they have no conflict of interest.

Ethical approval We certify that all applicable institutional and governmental regulations concerning the ethical use of human volunteers were followed during the course of this research.

Publisher's note Springer Nature remains neutral with regard to jurisdictional claims in published maps and institutional affiliations.

\section{References}

1. OECD. Sickness, disability and work: breaking the barriers. A synthesis of findings across OECD countries. Paris OECD publications: Paris. 2010.

2. Baumberg Geiger B, van der Wel KA, Tøge AG. Success and failure in narrowing the disability employment gap: comparing levels and trends across Europe 2002-2014. BMC Public Health. 2017; 17:928.

3. Van der Wel K, Halvorsen K. The bigger the worse? A comparative study of the welfare state and employment commitment. Work Employ Soc. 2014;28:1-20.

4. Lidal IB, Huyhn TK, Biering-Sørensen F. Return to work following spinal cord injury: a review. Disabil Rehabilit. 2007; 29:1341-75.
5. Ottomanelli L, Lind L. Review of critical factors related to employment after spinal cord injury: implications for research and vocational services. J Spinal Cord Med. 2009;32:503-31.

6. Krause JS, Reed KS. 2011. Barriers and facilitators to employment after spinal core injury: underlying dimensions and their relationship to labor force participation. Spinal Cord. 2011;49: 285-91.

7. Ferdiana A, Post MW, Van de Groot S, Bültmann U, van der Klink JJ. Predictors of return to work 5 years after discharge for wheelchair dependent individuals with spinal cord injury. J Rehabilit Med. 2014;46:984-90.

8. Solheim EF, Schedin Leiulfsrud A. Employment after Spinal Cord Injury in Norway: A Cross-Sectional Survey. Scand J Disabil Res. 2018;20:197-210.

9. Tomassen PCD, Post MWM, Asbeck FWA. Return to work after spinal cord injury. Spinal Cord. 2000;38:51-55.

10. Chen S, van der Klaauw W. The work disincentive effects on disability insurance program in the 1990s. J Econ. 2008;142: 757-84.

11. Kammer A, Niehuses, Peichl A. Welfare regimes and welfare state outcomes in Europe. J Eur Soc Policy. 2012;23:455-71.

12. Campos-Matos I, Kawachi I. Social mobility and health in European countries: does welfare regime type matter? Soc Sci Med. $2015 ; 142: 241-8$

13. Obinger H, Starke P, Moser J, Bogedan C, Gindulis E, Leibfried S. Switzerland: From Liberal to Conservative Welfare State a Pattern of Late Maturation. Oxford: Oxford Scholarship Online; 2010.

14. Heggeb $\emptyset \mathrm{K}$, Buffel V. Is there less labor market exclusion of people with Ill health in "flexicurity" countries? comparative evidence from Denmark, Norway, the Netherlands and Belgium. Int J Health Serv. 2019;49:476-515.

15. OECD. The Pursuit of Gender Equality: An Uphill Battle. Paris: OECD publications; 2017.

16. Eurostat 2019. https://ec.europa.eu/eurostat/web/lfs/data/main-ta bles Accessed 21 Aug 2019.

17. Andersen GE. The Incomplete Revolution: Adapting Welfare States to Women's New Roles. Cambridge: Polity Press; 2009.

18. Simandan D. Rethinking the health consequences of social class and social mobility. Soc Sci Med. 2018;200:258-61.

19. van de Mheen H, Stronks K, Schrjvers CTM, Machenbach JP. The influence of adult ill health on occupational class mobility and mobility out of and into employment in the Netherlands. Soc Sci Med. 1999;49:509-18.

20. Rose D, Harrison E, Pevalin D. The European Socio-economic Classification: a prolegomenon. In: Rose D, Harrison E, editors. Social Class in Europe: An introduction to the European Socioeconomic Classification. London, New York: Routledge; 2010. pp 3-38.

21. Cumming G, Finch S. Inference by the eye: confidence intervals and how to read pictured data. Am Psychol. 2005;60:170-80.

22. Bratberg E, Dahl SÅ, Risa AE. 'The Double Burden': Do Combinations of Career and Family Obligations Increase Sickness Absence among Women?. Eur Sociological Rev. 2002;18: 233-49.

23. Chen N, Conconi P, Perroni C. Women's Earning Power and the 'Double Burden' of Market and Household Work. CEPR Discussion Pap. 2007;No:DP6269.

24. Leiulfsrud AS, Ruoranen K, Osterman A, Reinhardt JD. The meaning of employment from the perspective of persons with spinal cord injuries in six European countries Work. 2016;55 133-44. 